\title{
POST-TRAUMATIC STRESS SYMPTOMS IN FATHERS OF VERY LOW BIRTH WEIGHT INFANTS AT 2 TO 4 YEARS POST-PARTUM
}

Amy Alexander ${ }^{1}$, Paul Clarke ${ }^{2}$, Imogen Hobbis ${ }^{1}$ and Kiki Mastroyannopoulou ${ }^{1}$

${ }^{1}$ Norwich Medical School, UEA, Norwich, UK; ${ }^{2}$ Neonatal Intensive Care Unit, Norfolk and Norwich University Hospital, Norwich, UK

\section{Background}

A very low birth weight (VLBW) infant weighs less than 1500 grammes. These infants need to be cared for in the neonatal intensive care unit (NICU). The birth and experiences in the NICU can often be extremely traumatic for parents. A traumatic event can result in posttraumatic stress disorder (PTSD). Posttraumatic stress symptoms (PTSS) refer to the presence of only some PTSD symptoms. Mothers of VLBW infants experience significantly higher rates of PTSS than mothers of full-term infants when assessed at 2 to 3 years postpartum (Åhlund et al., 2009).

\section{What about DAD?}

Fathers' needs are often unknown (White, 2007). There is a lack of research into PTSS in fathers of VLBW infants. Previous studies have mostly focused on immediate psychological impacts (e.g. Lefkowitz, Baxt, \& Evans 2010; Shaw et al., 2009). The aim of this study was to replicate the study by Åhlund et al. (2009), but assessing a group of fathers instead of mothers at 2 to 4 years postpartum.

\section{Research Questions}

1. Is there a difference in the levels of PTSS in fathers of VLBW infants and fathers of term infants 2 to 4 years postpartum?

2. What about anxiety and depression?

3. What is the impact of perceived social support?

4. How does the prevalence of PTSS in fathers and mothers of VLBW infants compare at 2 to 4 years?

\section{Method and Participants}

Questionnaire packs with a stamped addressed envelope for return were posted to 172 fathers of VLBW infants and 166 fathers of term infants born between 2011 and 2013. The measures sent were all validated and included:

- Impact of Events Scale-Revised - measuring PTSS related to the birth of their infant

- ENRICHD Social Support Inventory - measuring perceived social support at the time of the birth and hospitalisation of the fathers' infants

- Patient Health Questionnaire-9 - measuring current depression symptoms

- Generalised Anxiety Disorder Seven Item Scale - measuring current anxiety symptoms

Maternal comparison data at 2 to 3 years postpartum were from Åhlund et al. (2009), with kind permission.

Ethical approval was from the London-Fulham REC (ref. 15/LO/0947).

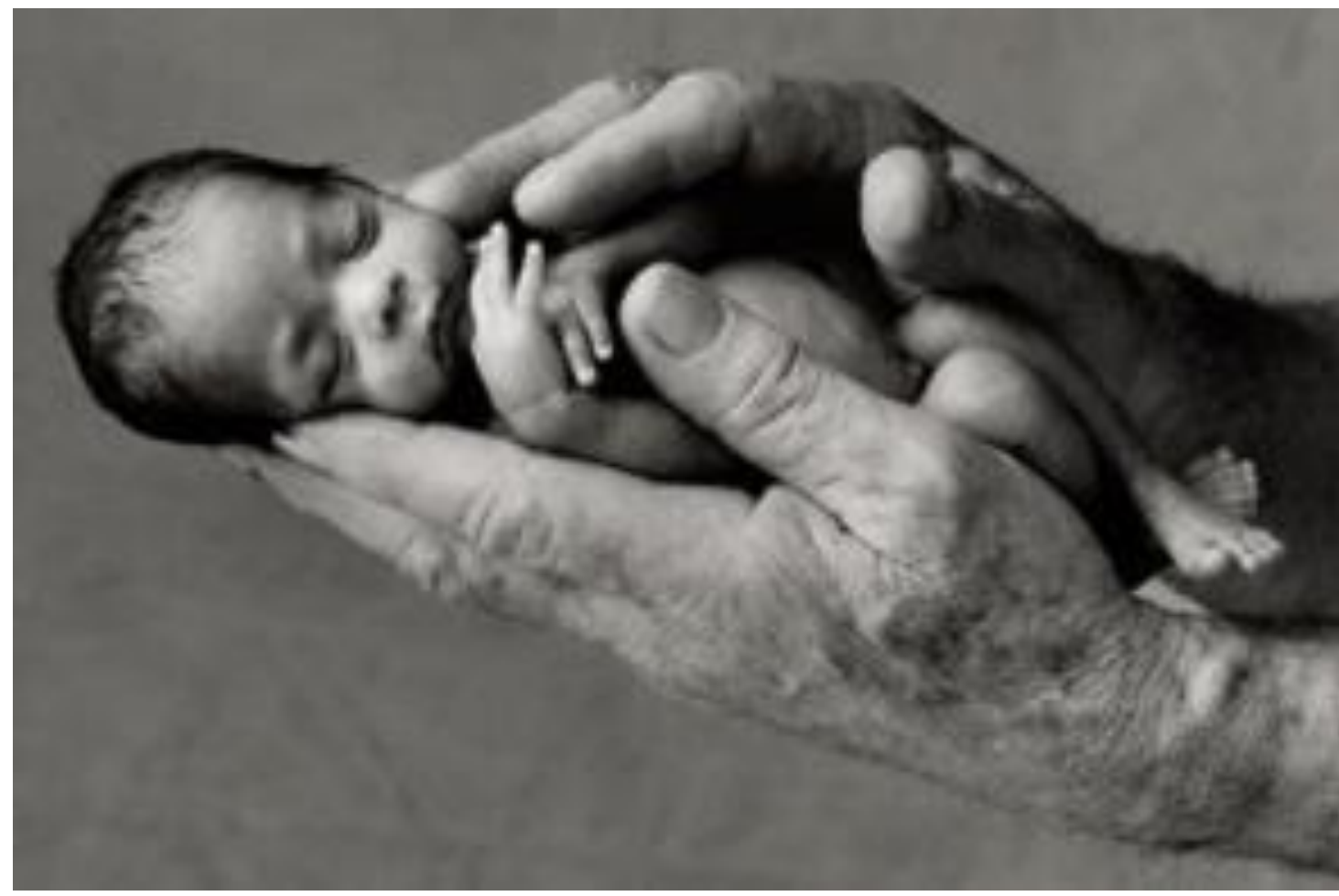

\section{Results}

26 fathers of VLBW infants and 22 fathers of term infants returned completed questionnaire packs; overall response rates were $15 \%$ and $13 \%$ respectively. Table 1 displays means and standard deviations for the infant demographic data.

Table 1. Infant Demographic Data - Mean (SD)

\begin{tabular}{lccc}
\hline & $\begin{array}{c}\text { Birth Weight } \\
\text { grammes }\end{array}$ & $\begin{array}{c}\text { Gestational Age } \\
\text { weeks }\end{array}$ & $\begin{array}{c}\text { Infant Age } \\
\text { years }\end{array}$ \\
\hline $\operatorname{VLBW}(n=26)$ & $1108(284)$ & $28.4(2.64)$ & $3.40(0.72)$ \\
Term $(n=22)$ & $3517(407)$ & $39.7(1.22)$ & $3.76(0.69)$ \\
\hline
\end{tabular}

Answers to the research questions were:

1. We found fathers of VLBW infants reported significantly higher levels of PTSS than fathers of term infants at 2 to 4 years postpartum (Table 2).

2. No significant differences were found between fathers of VLBW infants and fathers of term infants for anxiety and depression scores.

3. In the VLBW group, the fathers' perceived level of social support was significantly associated with lower PTSS scores; $\tau=-.31, \mathrm{n}=$ $26, p=.029$.

4. PTSS levels in fathers of VLBW infants were similarly high at 2 to 4 years compared with mothers of VLBW infants (Table 2).

Table 2. Impact of Events Scale-Revised scores in fathers and mothers at 2 to 4 years postpartum

\begin{tabular}{lccc}
\hline & VLBW & Term & p-value \\
\hline Fathers & $12.5 \dagger(3.0-27.0)$ & $0.5(0.0-3.0)$ & $<.001$ \\
& $(n=26)$ & $(n=22)$ & \\
Mothersף & $25.0(7.5-31.5)$ & $0.0(0.0-3.1)$ & $<.001$ \\
& $(n=24)$ & $(n=13)$ & \\
\hline
\end{tabular}

Data are median (IQR). ${ }^{*}$ Mann-Whitney test. tvs. mothers, $p=.08$. IData of Åhlund et al., 2009, with permission

\section{Conclusions and Future Directions}

- We show that fathers of VLBW infants are suffering PTSS as late as 2 to 4 years after the birth of their VLBW infants

- Fathers of VLBW infants had similarly high PTSS levels at 2 to 4 years postpartum as were present in mothers of VLBW infants at a similar postpartum age

- Increased psychological support is indicated for fathers following the birth of a VLBW infant

- More research is urgently needed into the experience and symptoms of trauma for fathers, potential family impact and how this may be best ameliorated

References
Åhlund, S., Clarke, P., Hill, J., \& Thalange, N. K. S. (2009). Post-traumatic stress symptoms in mothers of very low birth weight infants 2-3 years post-partum. Archives of Women's Mental Health, 12(4), 261-4.

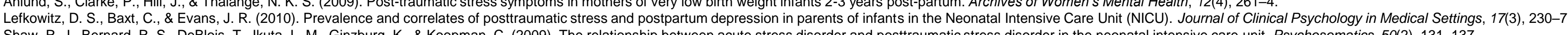
Shaw, R. J., Bernard, R. S., DeBlois, T., Ikuta, L. M., Ginzburg, K., \& Koopman, C. (2009). The relationship between acute stress disorder
White, G. (2007). You cope by breaking down in private: fathers and PTSD following childbirth. British Journal of Midwifery, 15(1), 39-45. 